\title{
Synergetic effect of onion (Allium cepa), tomato (Solanum lycopersicum) and garlic (Allium sativum) on in vitro iron bioaccessibility from cooked dehusked mungbean
}

\author{
Pardeep Kaur, Kiran Bains* and Harpreet Kaur \\ Department of Food and Nutrition, Punjab Agricultural University, (Ludhiana-141004), Punjab, INDIA \\ *Corresponding author. E-mail : kiranbains68@ hotmail.com
}

Received: November 11, 2015; Revised received: March 10, 2016; Accepted: June 1, 2016

\begin{abstract}
The usage of combination of onion (Allium cepa), tomato (Solanum lycopersicum) and garlic (Allium sativum) in legume preparations is vogue in North India but the amounts of these three additives need to be optimized to enhance iron bioavailability from the legumes. Four levels of the three additives were set where onion and tomato were added to $100 \mathrm{~g}$ of base legume i.e. dehusked mungbean (Vigna radiata) @ 25, 50, 75 and $100 \mathrm{~g}$ each while garlic was added @ 5, 10, 15 and $20 \mathrm{~g}$. The inclusion of the combination of onion tomato and garlic at levels Level 1 (4.55), Level 2 (5.37), Level 3 (5.80) and Level 4 (7.11) had a significantly $(p \leq 0.05)$ higher ascorbic acid level when compared to the legume with no additive $(0.26 \mathrm{mg})$. $\beta$-carotene content increased significantly $(p \leq 0.05)$ at all the levels $(15.42$ to $36.2 \mu \mathrm{g})$ when compared to the legume with no additive $(13.64 \mu \mathrm{g} / 100 \mathrm{~g}$ fresh weight) Similarly, the in vitro iron bioaccessibility increased significantly $(p \leq 0.05)$ when the level of fortification increased, the percent increase being 11.9, 14.1, 25.6 and $54.6 \%$ at Level 1, 2, 3 and 4, respectively when compared to the legume with no additive. The study concluded that the combination of onion $(100 \mathrm{~g})$, tomato (100g) and garlic $(20 \mathrm{~g})$ can enhance the bioaccessibility of iron from legumes maximally, hence, the observation can be useful in evolving dietary strategies to maximize the bioavailability of minerals from legumes.
\end{abstract}

Keywords: Dialyzable iron, Garlic, In vitro iron bioaccessibility, Onion, Tomato

\section{INTRODUCTION}

Eradication of iron deficiency anemia is an important goal of international community in order to improve nutritional and health status of the populations subsisting on cereal-legume based diets. This can be achieved by giving a right direction to the habitual meal patterns through fortification of common food preparations with optimized proportions of key foods known to enhance the bioavailability of iron. Inclusion of onion, garlic and tomatoes in legume preparations is practiced in Indian diets from times immortal. These additives have the evidence of being the enhancers of iron bioavailability (Gautam et al., 2010a, Gautam et al., 2011a and Bing et al., 2014). Garlic (Allium sativa) and onion (Allium cepa), which are liberally consumed in Indian diets, are rich sources of sulphur compounds such as thiosulfinates, sulfides, polysulfides, mercaptans and other odoriferous sulphur compounds. Both the allium species caused an increase in iron bioaccessibility ranging from $10-73 \%$ in different cereals and legumes (Gautam et al., 2010a). $\beta$-carotene, lycopene, lutein, beta cryptoxanthin and zeazanthin are some of the carotenoids present in appreciable amounts in tomatoes. These carotenoids have been demonstrated to improve iron absorption in vitro and in human absorption studies (Garcia-Casal, 2006) by providing a more soluble source of iron which is ready to be absorbed by regular pathways as well as by absorption through a carotenoid-iron complex. Tomato is also rich in organic acids which is known to promote the absorption of iron from plant foods (Hemalatha $e t$ al., 2005).

The majority of the rural and urban Indian households uses onion, tomato and garlic in combination rather than individually in most of the legume preparations (Kaur, 2015). There is sufficient work done on the independent effect of the each additive on the bioaccessibility of iron in food preparations however, the combined effect of three additives on in vitro iron bioaccessibility is not reported. The study aims to optimize the quantities of onion, tomato and garlic to be added to a base legume in order to enhance its iron bioaccessibility.

\section{MATERIALS AND METHODS}

Dehusked mungbean (Vigna radiata) was procured from the local market. One hundred grams of the legume was thoroughly washed and pressure cooked (15psi) in $350 \mathrm{ml}$ of water for 5 minutes. Salt, turmeric and red chilli powder were added at the rate of $2,1.5$ and $1.5 \mathrm{~g} / 100 \mathrm{~g}$, respectively. Inclusion of onion, garlic and 
tomato was made through sautéing (oil, 15g). The following five levels were set:

The experimental samples for all the levels were subjected to organoleptic evaluation using 9 point Hedonic

\begin{tabular}{llc}
\hline Level & Legume $(g)$ & $\begin{array}{l}\text { Combination }[\text { onion }(g)+ \\
\text { tomato }(g)+\text { garlic }(g)]\end{array}$ \\
\hline Level 0 & 100 & - \\
Level 1 & 100 & $25+25+5$ \\
Level 2 & 100 & $50+50+10$ \\
Level 3 & 100 & $75+75+15$ \\
Level 4 & 100 & $100+100+20$ \\
\hline
\end{tabular}

Scale. A panel of ten semi-trained judges evaluated the samples for their appearance, colour, taste, flavor, texture and overall acceptability. The cooked samples were homogenized in a stainless steel mixer and used for the chemical analysis. A portion of each homogenized sample was dried in hot air oven at $\pm 60^{\circ} \mathrm{C}$ till constant weight. The dried samples were ground and stored in decontaminated zip lock bags for the analysis. The experimental samples were prepared in three replicates for all estimations. The samples were examined for moisture (AOAC 1990), ascorbic acid (AOAC 1995), $\beta$-carotene (Rangana 1995) and cysteine (Liddell and Saville 1959). Total iron was determined by Atomic Absorption Spectrophotometer (AAS) after wet digestion. Bioaccessibility of iron from the samples was determined using in vitro method (Luten et al., 1996). This method for estimating food iron involves simulated gastrointestinal digestion followed by measurement of soluble, low molecular weight iron which diffused across a 6000 to 8000 molecular weight cutoff semi-permeable membrane and was used as an indicator of available iron.

Statistical analysis: Mean and standard deviations were computed for the data. Analysis of variance was employed to assess the synergetic effect of different levels of additives on in vitro iron bioaccessibility and other nutritional parameters.

\section{RESULTS AND DISCUSSION}

No significant difference in colour, appearance, flavor and texture was observed when the base legume was fortified with a combination of onion, tomato and garlic at all the four levels. However, Level 1 ranked first in colour, appearance and flavor and Level 4 for texture and taste. The taste score was found to be significantly $(\mathrm{p} \leq 0.05)$ higher at Level 4 when compared to Level 2. The overall acceptability of the legume preparation fortified at Level 1 was maximum followed by Level 4. The results showed that Level 1 and Level 4 had comparatively higher overall acceptability as compared to other two levels but the differences were statistically non-significant (Table 1). The inclusion of the combination of onion tomato and garlic at Level 1 (4.55), Level 2 (5.37), Level 3 (5.80) and Level 4 (7.11) had a significantly $(\mathrm{p} \leq 0.05)$ higher ascorbic acid level when compared to legume with no additive $(0.26 \mathrm{mg})$ as shown in Table 2 . The results indicated that though dehusked mungbean had negligible amount of ascorbic acid, the addition of onion, tomato and garlic contributed significantly $(\mathrm{p} \leq 0.05)$ to enhance ascorbic acid in the legume preparation. Ascorbic acid has been reported as a strong promoter of iron bioac-

Table 1. Organoleptic evaluation of a legume preparation fortified with combination of onion, tomato and garlic at different levels.

\begin{tabular}{llllllc}
\hline Code & Colour & Appearance & Flavor & Texture & Taste & Overall Acceptability \\
\hline L 1 & $8.2 \pm 0.63$ & $7.9 \pm 0.57$ & $7.8 \pm 0.42$ & $7.7 \pm 0.48$ & $7.6 \pm 0.52$ & $7.8 \pm 0.35$ \\
L 2 & $7.8 \pm 0.63$ & $7.7 \pm 0.67$ & $7.5 \pm 0.53$ & $7.5 \pm 0.53$ & $7.3 \pm 0.48$ & $7.6 \pm 0.46$ \\
L 3 & $7.6 \pm 0.52$ & $7.4 \pm 0.52$ & $7.8 \pm 0.42$ & $7.8 \pm 0.42$ & $7.7 \pm 0.48$ & $7.6 \pm 0.34$ \\
L 4 & $7.6 \pm 0.52$ & $7.5 \pm 0.53$ & $7.8 \pm 0.42$ & $7.9 \pm 0.32$ & $7.9 \pm 0.32$ & $7.7 \pm 0.27$ \\
C.D at 5\% & NS & NS & NS & NS & 0.50 & NS \\
\hline
\end{tabular}

Dehusked mungbean was used as base legume in all the experimental samples, C.D: Critical value, L1: Legume+ $25 \mathrm{~g}$ onion+ $25 \mathrm{~g}$ tomato $+5 \mathrm{~g}$ garli; L2: Legume+ $50 \mathrm{~g}$ onion $+50 \mathrm{~g}$ tomato $+10 \mathrm{~g}$ garlic, L3: Legume+ $75 \mathrm{~g}$ onion+ $75 \mathrm{~g}$ tomato $+15 \mathrm{~g}$ garlic L4: Legume+ $100 \mathrm{~g}$ onion+ $100 \mathrm{~g}$ tomato+ $20 \mathrm{~g}$ garlic

Table 2. Ascorbic acid, $\beta$-carotene, cysteine, methionine, total iron, dialyzable iron and \% in vitro iron bioaccessibility of a legume preparation fortified with the combination of onion, tomato and garlic at different levels.

\begin{tabular}{lllllll}
\hline Nutrients & Level 0 & Level 1 & Level 2 & Level 3 & Level 4 & C.D at 5\% \\
\hline Ascorbic acid, mg & $0.26 \pm 0.05$ & $4.55 \pm 0.13$ & $5.37 \pm 0.07$ & $5.80 \pm 0.15$ & $7.11 \pm 0.10$ & 0.21 \\
$\beta$-carotene, $\mu \mathrm{g}$ & $13.64 \pm 0.27$ & $15.42 \pm 0.27$ & $18.88 \pm 0.02$ & $23.88 \pm 0.07$ & $36.2 \pm 0.08$ & 0.28 \\
Cysteine, $\mathrm{mg}$ & $9.10 \pm 0.15$ & $12.14 \pm 0.09$ & $12.88 \pm 0.02$ & $13.16 \pm 0.16$ & $14.13 \pm 0.05$ & 0.22 \\
Total iron, mg & $5.19 \pm 0.05$ & $4.64 \pm 0.02$ & $4.70 \pm 0.07$ & $4.40 \pm 0.05$ & $4.01 \pm 0.08$ & 0.10 \\
Dialyzable iron, mg & $0.31 \pm 0.06$ & $0.31 \pm 0.08$ & $0.32 \pm 0.01$ & $0.33 \pm 0.04$ & $0.37 \pm .0 .02$ & 0.10 \\
$\begin{array}{l}\text { In vitro iron bioac- } \\
\text { cessibility, \% }\end{array}$ & $5.97 \pm 0.31$ & $6.68 \pm 0.20$ & $6.81 \pm 0.11$ & $7.5 \pm 0.15$ & $9.23 \pm 0.04$ & 0.37 \\
\hline
\end{tabular}

Values are on per $100 \mathrm{~g}$ dry matter basis for all the parameters except ascorbic acid and $\beta$-carotene, Dehusked mungbean was used as base legume in all the experimental samples, C.D: Critical value, Level 0: Legume + No additive, Level 1: Legume+ 25 $\mathrm{g}$ onion+ $25 \mathrm{~g}$ tomato+ $5 \mathrm{~g}$ garlic, Level 2: Legume+ $50 \mathrm{~g}$ onion $+50 \mathrm{~g}$ tomato+ $10 \mathrm{~g}$ garlic, Level 3: Legume+ $75 \mathrm{~g}$ onion $+75 \mathrm{~g}$ tomato+ $15 \mathrm{~g}$ garlic, Level 4: Legume+ $100 \mathrm{~g}$ onion+ $100 \mathrm{~g}$ tomato $+20 \mathrm{~g}$ garlic 


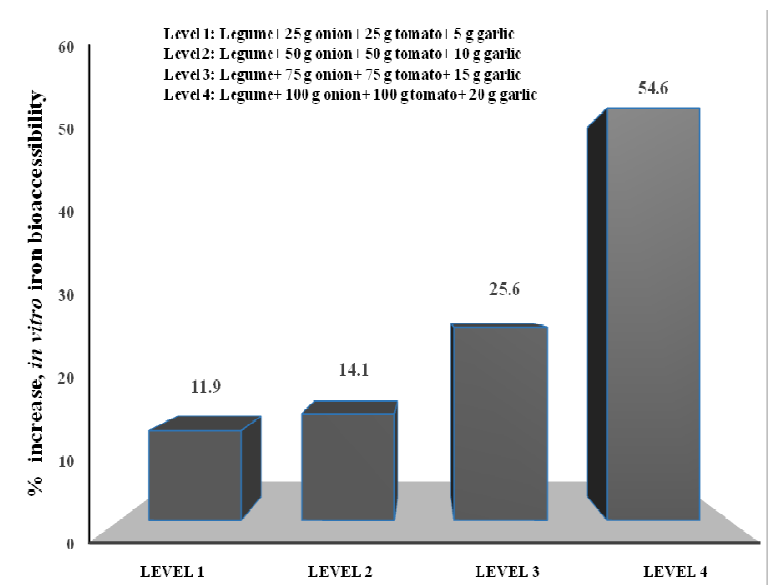

Fig. 1. Percent increase in the in vitro iron bioaccessibility of a legume preparation fortified with the combination of onion, tomato and garlic at different levels.

cessibility (Thankachan et al., 2008 and Lane and Richardson, 2014). The use of additives namely lemonade, amla juice, guava fruit, citrus fruit juices, potato, cauliflower or cabbages which are good sources of citric acid and ascorbic acid can enhance the iron bioaccessibility (Singh, 2013 and Venkatasubramanian et al., 2014). In addition to ascorbic acid, tomatoes also had $0.194 \mathrm{mg} \%$ of organic acids. Citric and malic acids are organic acids that contribute most to the typical taste of tomato fruit, other acids such as acetic, formic, trans-aconitic, lactic, fumaric, galacturonic, and a-oxo acids have also been detected (Salunkhe et al., 1974). These organic acids have been reported to enhance iron bioaccessibility in legumes (Hemalatha et al., 2005). The present study confirmed that the inclusion of tomatoes as a source of ascorbic acid and other organic acids may prove beneficial in enhancing the iron bioaccessibility from the food grains.

$\beta$-carotene content of the legume preparation fortified with onion, tomato and garlic increased significantly $(\mathrm{p} \leq 0.05)$ at all the levels $(15.42$ to $36.2 \mu \mathrm{g} / 100$ $\mathrm{g}$ fresh weight) when compared to the base legume with no additive as shown in table 2. Nambiar and Sharma (2014) stated that $\beta$-carotene content of garlic is $2377 \mu \mathrm{g} / \mathrm{g}$ whereas, Ahamad et al. (2007) reported $1610 \mu \mathrm{g} / 100 \mathrm{~g}$ of $\beta$ - carotene in tomatoes in fresh weight basis. $\beta$-carotene has been reported as a strong promoter of iron bioaccessibility in many reported studies (Garcia-Casal et al., 1998, Garcia-Casal et al., 2000 and Gautum et al., 2010b). The inclusion of onion, tomato and garlic at all levels had significantly $(\mathrm{p} \leq 0.05)$ higher cysteine content $(12.14$ to $14.13 \mathrm{mg})$ as compared to base legume with no additive (9.10 $\mathrm{mg}$ ) as shown in table 2. Cysteine has peptides responsible for enhancement of bioaccessibility of iron. Bing et al (2014) reported that two $\gamma$-glutamyl-cysteine peptides $\quad(\gamma$-GCPs $), \quad(S C 2 R C 7)-\gamma$ - $L$-glutamyl- $S$-allyl- $L$ cysteine and (SC2RC7)- $\gamma$-Lglutamyl- $S$-propyl- $L$ cysteine present in allium speices had a promoting effect on the bioaccessibility of iron from food.

Table 2 shows that the total iron content significantly $(p \leq 0.05)$ decreased with the inclusion of combination of onion, tomato and garlic at all levels, the values being 4.64 to $4.01 \mathrm{mg} / 100 \mathrm{~g} \mathrm{DM}$ as compared to base legume with no additive $(5.19 \mathrm{mg})$. Contrary to this, the dialyzable iron was maximum in Level 4 followed by Level 3, Level 2 and Level 1, the values being 0.37, $0.33,0.32$ and $0.31 \mathrm{mg} / 100 \mathrm{~g}$. These results clearly indicated that the fortification of onion, tomato and garlic in combination to the base legume significantly $(p \leq 0.05)$ increased the dialyzable iron when compared to the cooked legume with no additives. Promoters and inhibitors present in legumes influence the dialyzable iron content which represents the iron available to the human body. The increase in the dialyzable iron with onion fortification can be attributed to rich content of thiosulfinates, sulfides, polysulfides, mercaptans and other odoriferous sulfur compounds that has positive effect on iron bioaccessibility. Gautam et al., (2010a) found that onion had a significantly $(\mathrm{p} \leq 0.05)$ positive effect on the bioaccessibility of iron from cooked green gram and chickpea when added at two levels i.e. 15 and $30 \mathrm{~g}$ per $100 \mathrm{~g}$ of the legume.

The bioaccessibility of iron in cooked green gram was increased by 17.2 and $32 \%$ while for cooked chickpea it was increased by 21.2 and $26.3 \%$ at the two levels, respectively. Another study conducted by Gautam et al., (2011a) showed that phytic acid decreased the bioaccessibility of iron from raw green gram by $30 \%$, while onion increased it by $28 \%$. The positive effect of onion was predominant even in the presence of phytic acid, and this combination produced a net increase in iron bioaccessibility by $21 \%$. Similarly, the combination of onion and phytic acid had a net positive influence of $30 \%$ in iron bioaccessibility from cooked green gram, whereas phytic acid independently had a negative influence by $27 \%$, and onion had a positive influence by $31 \%$. Thus, onion completely overcame the negative influence of phytic acid on iron bioaccessibility from green gram, and also retained the extent of its positive influence. Garcia- Casal (2006) reported that lycopene, lutein, and zeaxanthin without provitamin-A activity in presence of different concentrations significantly $(\mathrm{p} \leq 0.05)$ increased in vitro iron absorption in human absorption studies from corn and wheat meals. The in vitro iron bioaccessibility was significantly $(p \leq 0.05)$ higher when the cooked legume was fortified with onion, tomato and garlic at Level 4 followed by Level 3, 2 and 1, the values being 9.23, 7.50, 6.81 and 6.68 , respectively (Table 2 ). The percent increase in vitro iron bioaccessibility was 11.9, 14.1, 25.6 and $54.6 \%$ at Level 1, Level 2, 3 and 4, respectively when compared to the base legume (Fig. 1). Bing et al. (2014) revealed that upon the addition of $0.01 \mathrm{mmol}$ compound $\gamma$ - $L$-glutamyl- $S$-allyl- $L$-cysteine, the bioavailability of iron in mung bean was increased from $2.52 \%$ to $12.04 \%$ with the percentage increase in 
the bioavailability of iron from mung bean being $380 \%$. Gautam et al 2010a reported that garlic enhanced iron bioaccessibility from cooked green gram to 60.6 and $73.3 \%$ at the two levels i.e. 2.5 and $5.0 \mathrm{~g}$ per $100 \mathrm{~g}$ of the legume, respectively. In the case of cooked chickpea, garlic enhanced the bioaccessibility of iron by 10 and $17.2 \%$ in cooked grains at the two levels, respectively.

\section{Conclusion}

The study concluded that the synergistic effect of onion tomato and garlic at different levels i.e. 25 to $100 \mathrm{~g}$ for onion and tomato and 5 to $20 \mathrm{~g}$ for garlic was well pronounced as the percent increase of in vitro iron bioaccessibility by 11.9 to $54.6 \%$ was observed. The observations from the study can be useful in evolving dietary strategies to maximize the bioavailability of minerals from legumes in order to address the problem of iron malnutrition.

\section{REFERENCES}

Ahamad, M.N., Saleemullah, M., Shah, H.U., Khalil, I.A. and Saljoqi, A.U.R. (2007). Determination of beta carotene content in fresh vegetables using high performance liquid chromatography. Sarhad J. Agric., 23: 767-770.

AOAC. (1990). Official Methods of Analysis. Association of Official Analytical Chemists. Washington D.C.

AOAC. (1995). Official Methods of Analysis. Association of Official Analytical Chemists International. Arlington, pp16-18.

Kaur, P. (2015). Optimization of onion, garlic and tomato fortification in traditional legume preparations for enhanced iron bioaccessibility. M.Sc. Thesis, Punjab Agricultural University, Ludhiana.

Bing, B.A.I., Lu-Lu, C.H.E.N., Qiao-Lian, L.I., Ya-Qi, D.U.A.N., Ling, L.I.U., De-Hong, T.A.N. and ShuJuan, J.I. (2014). Preparation and functional exploration of cysteine peptides from fresh garlic scales for improving bioavailability of food legume iron and zinc. Chin. J. Anal. Chem., 42: 1507-1512.

Garcia-Casal, M.N., Layrisse, M., Solano, L., Baron, M.A., Arguello, F., Llovera, D., Ramiirez, J., Leets, I. and Tropper, E. (1998). Vitamin A and $\beta$-carotene can improve non-hemeiron absorption from rice, wheat and corns by humans. J. Nutr., 128: 646-650.

Garcia-Casal, M.N., Leets, I. and Layrisse, M. (2000). $\beta$ carotene and inhibitors of iron absorption modify iron uptake by Caco-2 cells. J Nutr., 130: 5-9.

Garcia-Casal, M.N. (2006). Carotenoids increase iron absorption from cereal based food in the human. Nutr. Res., 26:
340-344.

Gautam, S., Platel, K. and Srinivasan, K. (2010a). Higher bioaccessibility of iron and zinc from food grains in the presence of garlic and onion. J. Agri. Food Chem., 58: 8426-8429.

Gautam, S., Platel, K. and Srinivasan, K. (2010b). Influence of $\beta$-carotene rich vegetables on the bioaccessibility of zinc and iron from food grains. Food Chem., 122: 668672.

Gautam, S., Platel,K.and Srinivasan, K. (2011a). Influence of combinations of promoter and inhibitor on the bio accessibility of iron and zinc from food grains. Int. J. Food Sci. Nutr., 62: 826-834.

Hemalatha, S., Platel, K. and Srinivasan, K. (2005). Influence of food acidulants on bioaccessibility of zinc and iron from selected food grains. Mol. Nutr. Food Res., 49: 960-965.

Lane, D.J. and Richardson, D.R. (2014). The active role of vitamin $\mathrm{C}$ in mammalian iron metabolism: Much more than just enhanced iron absorption. Free Radical Biol. Med., 75: 69-83.

Liddell, H.P. and Saville, B. (1959). Colorimetric determination of cysteine. Analyst., 84: 188-190.

Luten, J., Crews, H., Flynn, A., Dael, P. V., Kastenmayer, P., Hurrel, R., Deelstra, H., She,n L.H., FairweatherTait, S., Hickson, K., Farre, R., Schlemmer, U. andFrohlich, W. (1996). Inter-laboratory trial on the determination of the in vitro iron dialyzability from food. $J$. Sci. Food Agric., 72: 415-424.

Nambiar, V.S. and Sharma, M. (2014). Carotene content of coriander leaves (Coriandrumsativum), amaranth, red (AmaranthusSp), green garlic (Allium sativum) and mogri (Raphanuscaudatus) and its products. J. App. Pharm Sci., 4:69-74.

Rangana, S. (1995). Manual of analysis of fruit and vegetable products. Tata Mcgraw-Hill Publishing Company Limited, New Delhi.

Salunkhe, D.K., Jadhav, S.J. and Yu, M.H. (1974). Quality and nutritional composition of tomato fruit as influenced by certain biochemical and physiological changes. Plant Foods Hum. Nutr., 25: 85-113.

Singh, A. (2013). Enhancement of bioavailable iron in the meals of adult women. Ph.D. Dissertation, Punjab Agricultural University, Ludhiana, India.

Thankachan, P., Walczyk, T., Muthayya, S., Kurped, A.V. and Hurrell RF (2008). Iron absorption in young Indian women: the interaction of iron status with the influence of tea and ascorbic acid. Am. J. Clin. Nutr., 87: 881-886.

Venkatasubramanian, P., Koul, I.B., Varghese, R.K., Koyyala, S. and Shivakumar, A. (2014). Amla (Phyllanthusemblica L.) enhances iron dialyzability and uptake in in vitro models. Current Sci., 107: 1859-1866. 